Information Technology in the Home: Barriers, Opportunities, and Research Directions

\author{
Rosalind Lewis
}

IP-203

October 2000

Prepared for the PATH (Partnership for Advancing Technology in Housing) and the White House Office of Science \& Technology Policy (OSTP).

\title{
Science and Technology Policy Institute
}

RAND issue papers explore topics of interest to the policymaking community. Although Issue Papers are formally reviewed, authors have substantial latitude to express provocative views without doing full justice to other perspectives. The views and conclusions expressed in Issue Papers are those of the authors and do not necessarily represent those of RAND or its research sponsors. 


\section{Contents}

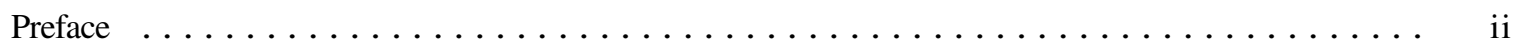

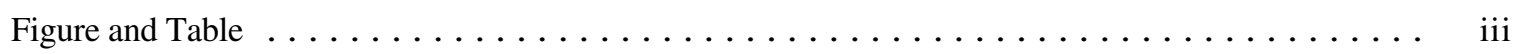

Glossary ............................... iv

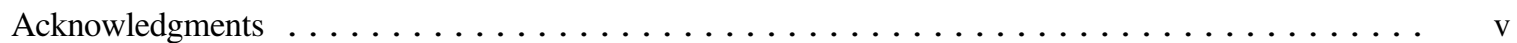

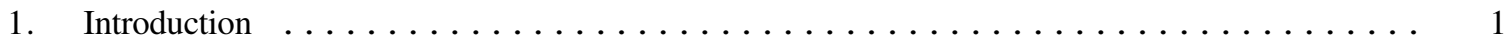

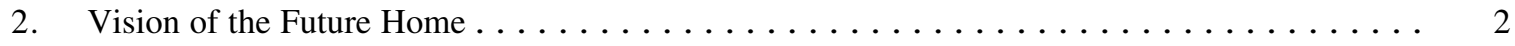

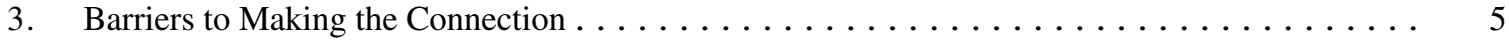

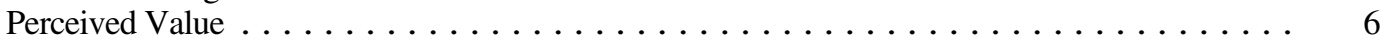

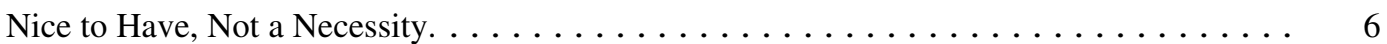

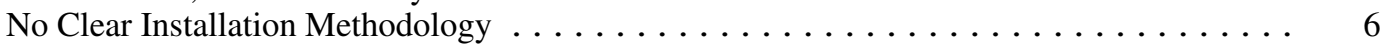

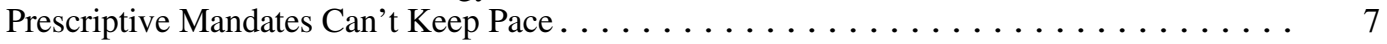

Limited Skilled-Labor Pool $\ldots \ldots \ldots \ldots \ldots \ldots \ldots \ldots$

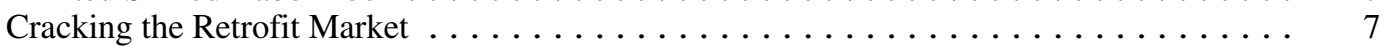

Service Provider Confusion $\ldots \ldots \ldots \ldots \ldots \ldots \ldots \ldots \ldots$

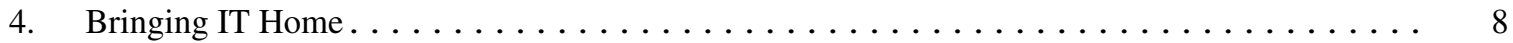

Where Are We Now $\ldots \ldots \ldots \ldots \ldots \ldots \ldots \ldots \ldots \ldots \ldots \ldots$

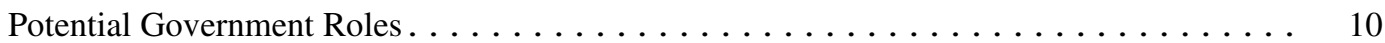

Support Standard-Setting Activities $\ldots \ldots \ldots \ldots \ldots \ldots$

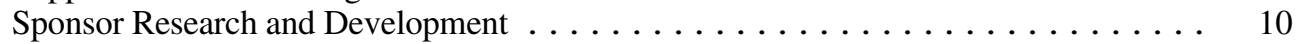

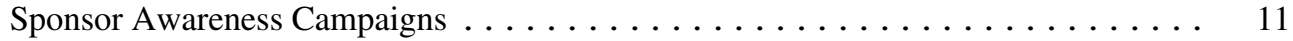

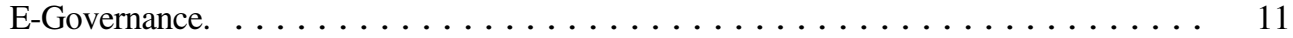

Provide Incentives $\ldots \ldots \ldots \ldots \ldots \ldots \ldots \ldots \ldots \ldots \ldots$

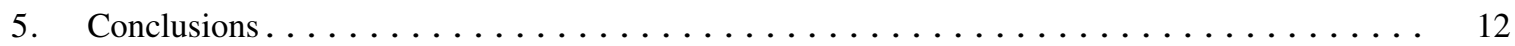

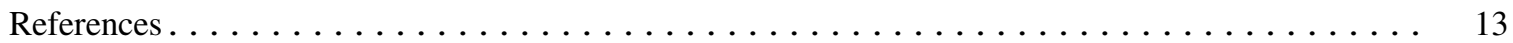

Appendix A: Roundtable Participants .......................... 14

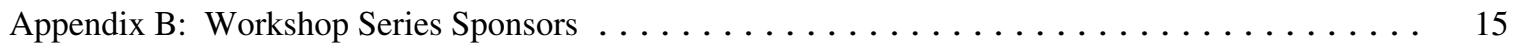




\section{Preface}

\section{This Analysis}

The home building, telecommunications, and consumer electronics industries are rapidly converging on America s doorstep to provide connectivity, access, and services; but what are the implications of increased Information Technology (IT) in the home? Can increased in-home IT create opportunities that will change the way we live and function within our homes and communities and facilitate greater societal benefits? Will the public embrace in-home IT to the extent required to bring about such change? Is there a role for government to play? To address these questions, RAND conducted background research and hosted a roundtable discussion at which participants established a set of policy issues and recommendations. The roundtable was held to provide information for the Partnership for Advancing Technology in Housing (PATH), a public/private initiative, and was sponsored by the White House Office of Science \& Technology Policy (OSTP).

This issue paper discusses the barriers, opportunities, and research directions for in-home IT distilled from the roundtable, related industry events, and other sources. The intent is to provide a preliminary framework for appropriate government roles that will enable interested parties to advance the concepts of in-home IT and thereby realize the larger societal benefits that can result from technological advances.

\section{The S\&T Policy Institute}

Originally created by Congress in 1991 as the Critical Technologies Institute and renamed in 1998, the Science and Technology Policy Institute is a federally funded research and development center sponsored by the National Science Foundation and managed by RAND. The Institute s mission is to help improve public policy by conducting objective, independent research and analysis on policy issues that involve science and technology. To this end, the Institute

- $\quad$ supports the Office of Science \& Technology Policy and other Executive Branch agencies, offices, and councils;

- helps science and technology decisionmakers understand the likely consequences of their decisions and choose among alternative policies; and

- helps improve understanding in both the public and private sectors of the ways in which science and technology can better serve national objectives.

Science and Technology Policy Institute research focuses on problems of science and technology policy that involve multiple agencies. In carrying out its mission, the Institute consults broadly with representatives from private industry, institutions of higher education, and other nonprofit institutions.

Inquiries regarding the Science and Technology Policy Institute may be directed to the addresses below.

Bruce Don

Director

Science and Technology Policy Institute

\begin{tabular}{|c|c|c|}
\hline S c i e n c e & Tec h n o l o g y & I n s t i t u t e \\
\hline RAND & & $413-1100 \quad x 5351$ \\
\hline 1200 South Hayes Street & & Web: http://www.rand.org/centers/stpi \\
\hline Arlington, VA $22202-5050$ & & Email: stpi@rand.org \\
\hline
\end{tabular}




\section{Figure}

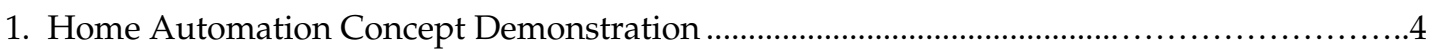

\section{Table}

1. Percentage of U.S. Households with Telephone, Computer, and Internet Use: 1994, 1997,1998 


\section{Glossary}

AHAM

ATA

CABA

DSL

EHE

EIA

FCC

FHA

HAA

HTML

ICCE

ISP

IT

ITAC

Mbps

NAHB Research Center

OSTP

PATH

SIP

WAP
Association of Home Appliance Manufacturers

American Telemedicine Association

Continental Automated Buildings Association

digital subscriber line

Electronic House Expo

Electronic Industries Association

Federal Communications Commission

Federal Housing Administration

Home Automation Association

hypertext mark-up language

IEEE International Conference on Consumer Electronics

Internet service provider

information technology

International Telework Association \& Council

megabits per second

National Association of Home Builders Research Center

White House Office of Science \& Technology Policy

Partnership for Advancing Technology in Housing

structural insulated panels

wireless application protocol 


\section{Acknowledgments}

The author wishes to express her appreciation to Tora Bikson and Scott Hassell for their many helpful insights and suggestions. 


\section{Information Technology in the Home: Barriers, Opportunities, and Research Directions}

\section{Introduction}

The elderly and rather fragile woman living across the street had a medical appointment today. After checking her vital signs, blood sugar, and the jubilant smile on her face, her doctor issued her a clean bill of health and scheduled her next appointment. Just then, he looked up from his morning paper to see if the bus was approaching. Seeing that the next bus was at least ten minutes away, he returned to reading. Meanwhile, a promising high school athlete discussed his goals with the college athletic director, as they reviewed the video highlight clips of his football season this past year.

There is nothing unusual about these scenarios except for the notion that they all occurred without anyone ever leaving home. They are all examples of what the future may hold in this, the information age. The information age didn $\mathrm{t}$ just arrive, it s been around for quite some time; but it has been rapidly maturing, and its latest target is America s doorstep. Pagers, computers, and the Internet, all based on technology that is more than 25 years old, were previously confined to academic, R\&D, military, and government institutions. As technology began to offer improved, more efficient operations, the information revolution took hold in the business sector. Now, with the increased availability and affordability of technology that can collect, store, process, and transmit information, homes are poised to experience a phenomenal change.

The code word in Information Technology (IT) today is smart. There are smart cards, smart appliances, smart corridors, and, of course, smart homes. And according to some, the home is about to become very smart. The features that make a home smart are debatable, since the term is applied to everything from home security systems to distributed content to remotely voice-activated Internet- able devices. However one defines smart, the thing that undoubtedly enables a smart home is the existence, at some level, of a network facilitating enhanced communications, control, or information-sharing throughout and beyond the home. This electronic nervous system is now being compared to previous technological advances that revolutionized American life-styles: A house without an In-Home Network will be as out-of-date as a house without electricity was less than a century ago! (Wizer Systems, 1999).

Lately, home networking has been the hot topic in many IT-related industry circles. In March 2000, the Home Automation Association (HAA) ${ }^{1}$ co-sponsored the Electronic House Expo (EHE), subtitled Fast Forward to the Connected Home! In May, the fourth incarnation of CONNECTIONS ${ }^{\mathrm{TM}} 2000$ was held; its subject was Advancing the Networked Home. ${ }^{2}$ The Association of Home Appliance Manufacturers ${ }^{3}$ (AHAM) held a two-day conference to address the impact of home networking on appliances and retail, partially in recognition of the fact that the technology to make home automation feasible has arrived. And most recently, the IEEE International Conference on Consumer Electronics (ICCE), which focuses on new advances in connectivity products, had sessions dedicated to home networking and related technologies.

These events, considerable research, and a generation of Americans who are just as likely to ask Can I go on-line? as Can I go outside? suggest that in-home IT and networking are more than a passing fad. Sustaining this belief are predictions of increased consumer demand for Internet access, as well as burgeoning business strategies designed to exploit this newest mile of the information highway. The implicit assumption here is that access matters. There may not be sufficient data to determine the importance of access, but clearly the ability to connect is central to realizing many benefits of IT in the home. Applications designed to save time, conserve resources, reduce costs, and improve services are less effective without connectivity to provide access, share data, enable control, or facilitate communication across devices as well as between them and their users. The dilemma is that while

\footnotetext{
${ }^{1}$ The HAA, founded in 1988 , is the trade association of the home control industry. It currently has more than 300 company members, including manufacturers, distributors, dealers, installers, and service providers of home automation products.

${ }^{2}$ This event was co-sponsored by CABA (the Continental Automated Buildings Association) and Parks Associates, a consumer research and industry analysis firm that studies and forecasts the home networking and broadband industries. The goal of the event was to encourage the development, promotion, and adoption of business opportunities in the home and building automation industry.

${ }^{3}$ AHAM represents the manufacturers of home appliances and is an information source for consumers about who buys and uses home appliances, and for the business executive whose work involves the home-appliance industry.
} 
connectivity is fundamental, the idea of networking to, from, and within the home currently is a personal decision based on perceived value versus cost and technological challenges.

Assuming connectivity is critical and here to stay, what are its implications for the way we live, work, play, and interact? Are there applications and services for the home that have the potential to improve the quality of life or ease societal burdens? What will it take for these to be effective? Will these concepts reach the average house ? How do we get there? Is there a role for government to play? The approach we used to address these questions involved several steps. First we conducted background research to better understand the status of IT in the home. Then we assembled a panel of experts from various fields to discuss the promise and challenges of increased inhome IT. Finally, we combined information by looking for recurring themes or ideas. In particular, we looked for concepts of what a home enhanced by IT might offer (benefits), infrastructures that would be required (challenges), and areas where government might be able to help (opportunities).

Several strategies were used to understand the status of in-home IT. By searching for terms such as smart home, home automation, home networking, and combinations thereof, we uncovered products and services geared toward the in-home IT market. We also looked for groups and organizations that promote the advancement or utilization of in-home IT, such as the American Telemedicine Association (ATA) ${ }^{4}$ and the International Telework Association \& Council (ITAC). ${ }^{5}$ Finally, we participated in events such as the EHE and talked to representatives from AHAM to learn about the challenges of in-home IT from an industry perspective.

Based on the perceived problems and issues we identified, we generated a brief position statement to solicit participation as well as set the agenda for roundtable panel discussions. On May 16, 2000, representatives from residential construction, education, transportation, energy, computing/networking, behavioral sciences, academia, and government convened to exchange ideas about the future home, the enabling technologies, and ways to bring IT into the home. ${ }^{6}$ The participants are listed in Appendix A.

This issue paper explores the potential ways in which government can facilitate the transition of technology into the home to improve the overall quality of life for all citizens and, where possible, to advance the goals of the Partnership for Advancing Technology in Housing (PATH) affordability, energy efficiency, environmental performance, durability, ease of maintenance, enhanced safety, and disaster resistance (see Appendix B). In short, PATH, a public/private initiative, and its partners strive to improve the quality of new and existing homes. In this paper, we have adopted a broad use of the term home, without making distinctions on the basis to location (urban, suburban, rural) or type of residence ${ }^{7}$ (townhouse, condominium, detached home, etc). Finally, the term household is used to represent the set of people that occupy the home.

In the following sections, the information and concepts we obtained are synthesized to suggest barriers, opportunities, and research directions for in-home IT. Section 2 reviews the types of applications and services made possible by increased connectivity. Section 3 enumerates some of the technical and social impediments to increased in-home IT. Section 4 lists potential roles the government could assume to foster widespread deployment of these technologies. Section 5 concludes with a recommended set of primary steps for government action and restates the key tenets of the paper.

\section{Vision of the Future Home}

Presenters at the EHE frequently asserted that the in-home network is currently driven by security, entertainment, and shared Internet access. ${ }^{8}$ Many people may not consider these activities, with the exception of shared Internet access, as examples of networking, but security systems, for example, exhibit two basic features of networking: the ability to disseminate information and the sharing of resources. Security systems link geographically dispersed data-

\footnotetext{
${ }^{4}$ The ATA is a nonprofit organization that promotes greater access to medical care for consumers and health professionals via telecommunications technology.

${ }^{5}$ The ITAC is a nonprofit organization dedicated to promoting the economic, social, and environmental benefits of telework

(www.telecommute.org).

${ }^{6}$ This was the second in a series of workshops hosted by RAND and co-sponsored by RAND, the NAHB Research Center, the White House Office of Science and Technology Policy, and the Partnership for Advancing Technology in Housing.

${ }^{7}$ Multiunit apartment dwellings were not explicitly addressed in the roundtable discussions.

${ }^{8}$ Shared Internet access allows multiple devices to use the Internet simultaneously via a single connection, eliminating the need to replicate modems, telephone lines, and ISP accounts for each device.
} 
collection units (sensors) to a local system (control panel/box), which then communicates via a separate system (telephone lines) to provide information to a regional control center. This is probably not what consumers are thinking about when they sign a service contract, however. They are probably thinking about the peace of mind the security system will bring to them and their family. They have adopted the technology because of its perceived value.

In the future, the in-home network will have many more reasons to exist, as applications and services will be targeted not only to every home and every person, but also to every thing. Whether the goal is to find more uses for processing technology or to add value in consumer electronics to re-penetrate an already saturated market, networking seems to be the direction in which everything is headed. Listed below are just a few existing and potential applications.

- Home controls, or "digital butlers":

- Heating, cooling, and lighting systems or devices remotely controlled via the Internet, so that if a person forgets to turn something off before leaving home, he or she can sign on and shut off the outlet from any location.

- $\quad$ Systems and/or devices that go on and off automatically, adjusting to household routine by observation or access to on-line information sources (e.g., schedules, weather forecasts, electricity prices).

- $\quad$ Configuration of the home environment using verbal commands or biotechnology cues.

- $\quad$ Front doors that use biometric data and automatically open for household members as they approach.

- Safety/security systems covering a range of applications designed to provide protection and avoid accidents:

- Systems that summon emergency help in response to voice commands.

- Televisions that interrupt programming to display a picture of anyone approaching the front door.

- Preventive maintenance monitoring to help detect or avoid problems such as leaks or termites.

- Connected devices that can be monitored and controlled from practically anywhere.

- Home office.

- Multiple and simultaneous use of a single Internet connection (and peripheral devices) in support of homebased businesses and telecommuting, thereby reducing traffic congestion, air pollution, and energy consumption.

- Health care/wellness care.

- Telehomecare (medical care in the home using telemedicine techniques) for elders, the homebound, or others who need routine services. ${ }^{9}$

- In-home health management technology (e.g., devices that record medical history data and routinely report to a health-care provider) to assist young people and families to live a healthy and active lifestyle.

- Enhanced access to medical resources for monitoring, diagnosis, therapy, and education.

- Distance or tele-learning via an increasing array of technological options for the delivery and receipt of instruction and educational resources, providing educational opportunities to anyone, at any place, at any time.

- Transportation management to encourage ridership on and increase the convenience of public transportation by providing information such as real-time schedules and location status; home devices that track buses and trains to inform the elderly or school children when the bus is coming, making public transit easier, safer, and more reliable.

- Energy conservation and resource load-sharing via heating and cooling controls that allow the utilities to temporarily adjust homeowners temperature settings via the Internet during peak demand times to reduce energy usage.

- Interactions with government agencies that allow people to file taxes, apply for licenses, obtain building permits, complete census forms or employment applications, and access information. For example, ServiceArizona, a four-year old project, allows the local government to conduct a number of web-based transactions such as ordering personalized license plates and replacing lost ID cards (Symonds, 2000).

${ }^{9}$ According to the ATA, this application has probably one of the greatest potentials for rapid growth worldwide. (See American Telemedicine Association, 1999.) 
- Communication and interaction with family and friends.

- Video e-mailing and video chats connected through home entertainment systems.

- Household on-line calendars and/or access to navigation information that enables family members to locate one another.

- Access for e-commerce, asset and personal management, and entertainment.

This list reflects existing ideas or concepts that are actively being considered in response to and in anticipation of increased connectivity. For example, Figure 1, from an EHE vendor, presents one vision of how the future home will make life easier. This vision is primarily focused on safety, physical security, and convenience items that are likely to be an easy sell to the consumer. However, the amount of interaction, both internally and externally, among the devices as well as among people implies a level of connectivity for which the average house is currently unprepared.

\section{Figure 1: Home Automation Concept Demonstration Source: Invensys Network Systems}

\begin{abstract}
Home Manager ${ }^{\mathrm{TM}}$ software offers a variety of modes such as Vacation, At Work, and Home Alone (for young family members). Desired room temperatures, lighting, irrigation, and other system options easily are configured and stored for each.
\end{abstract}

Portable touchpad allows access to system. Send and receive e-mail, check news, weather, status of washer, oven, and other devices, or call up daily schedule of any family member. Audible beep and window on screen signal when laundry or dinner is ready.

\begin{abstract}
Activity in other areas of house can be monitored from room switch plates. Switch plates display room temperature and provide access to system settings, allowing comfort customization for each room.
\end{abstract}

Visitors can leave audio and visual messages with Door Butler. Flashing icon on switch plate indicates message waiting. TV and monitors throughout home display image of caller at front door.

Activity of children or the elderly can be monitored from remote location. Two-way video and audio travels through system portals or entertainment center TV set.

Family Manager helps members coordinate and organize activities and events. Verbal notes, instructions, or directions can be attracted. Displays and announces a series of to-do items for each family member. Delete items easily, or add by the press of a button and speaking.

Lights can be programmed to switch off and on in different locations during selected periods, such as 8:30 a.m. to 11:00 p.m., to simulate activity while away from home.

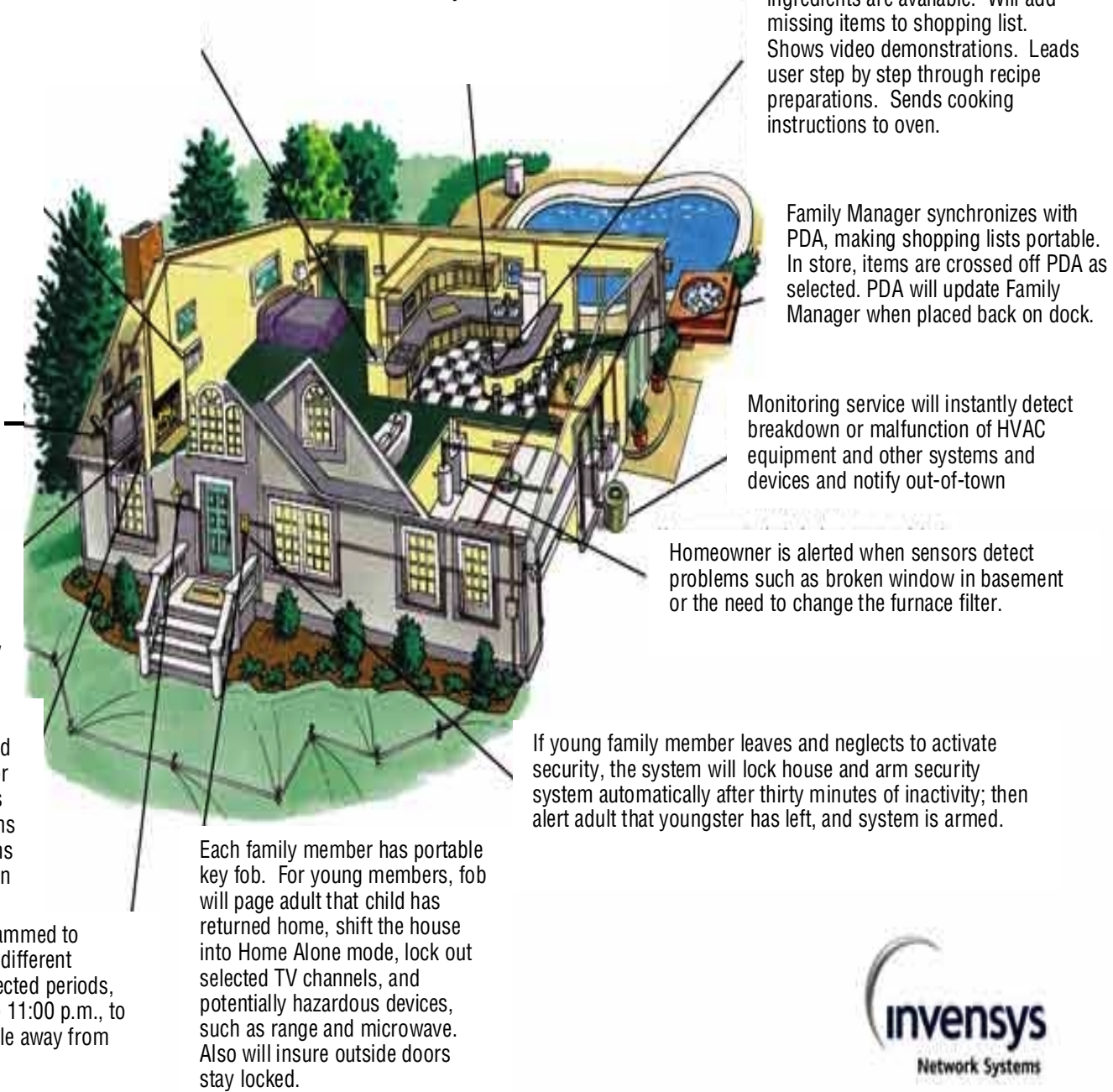

Kitchen Assistant software can be accessed from portable touchpad or other system portals. Provides menu suggestions. Indicates what ingredients are available. Will add missing items to shopping list. Shows video demonstrations. Leads step by step through recipe preparations. Sends cooking Family Manager synchronizes with PDA, making shopping lists portable. selected. PDA will update Family Manager when placed back on dock.

Monitoring service will instantly detect breakdown or malfunction of HVAC equipment and other systems an devices and notify out-of-town stay locked. 
It is not possible to predict all the future applications and services that will emerge for the home, but history has shown via telephony, radio, and television that changes in communication bring about changes in society. And as with previous technological advances, increased in-home IT and connectivity will undoubtedly have both positive and negative consequences. ${ }^{10}$ But if its advantages are equally available to all, in-home IT could be a great equalizer, giving more people broader access to educational, health, and economic activities. It may provide increased opportunities for efficient governance and resource usage. It may bring together families, neighborhoods, and communities by transcending real-world boundaries that inhibit interaction. If the benefits of connectivity begin to materialize, in-home IT may actually become a modern-day home necessity as important as water, electricity, or the telephone.

The possibilities have led many to term connectivity the new utility. ${ }^{11}$ The expectation is that an affordable and comprehensive infrastructure, analogous to that for the traditional utilities, will someday be available to most, if not all, portions of society, ushering in a host of information and communication services. Many elements of that infrastructure exist today. In-home networking can be accomplished via a variety of wired or wireless techniques. For some applications, existing electrical and telephone wires and coaxial cable can be used to transfer data and control messages without interfering with the primary service. If these techniques are combined with management and control systems, they offer the potential to drastically change the way people live in and interact with their homes. Commerce and the demand for high-speed Internet connections are driving the competition for the pipe to the home and creating a myriad of consumer options. Dial-up, DSL ${ }^{12} /$ cable modems, and residential gateways represent a few of the ever-expanding alternatives for connecting the in-home network to the Internet. But if connectivity is to be the fourth utility, ${ }^{13}$ it has some growing up to do.

\section{Barriers to Making the Connection}

The quality of life in the future home may dramatically improve as more and more IT applications are implemented, but the value proposition for connectivity is nontrivial at this point. A roundtable participant noted that people are being asked to buy into a system, as opposed to a product (e.g., a VCR). And unlike a telephone or a television set, the basic form, fit, and function of the in-home network are still evolving. Many people perceive the system as too complex to use and deploy, or even to evaluate. Participants further suggested that people don $t$ invest in things that don $t$ appear stable and they don $t$ maximize the cost-benefit analysis; they satisfy their needs. They have pragmatic concerns and want a good out of the box experience (i.e., it will work when they get it home). They want to believe they ve made a good investment and have reservations about throwing away tomorrow what they buy today.

Connecting every home so it can do everything is expensive and may be unwarranted. If buying into the system is too complex, perhaps it is reasonable to consider a modular approach, recognizing that benefits can come incrementally. This requires scalable solutions for consumers, so that they can examine the technology that will provide a level of functionality they are comfortable with and willing to pay for. For example, a basic building block of the system could be as simple as any device providing fast Internet access with some local memory for data storage. Today, the typical device for accessing the Internet in the United States is a personal computer, ${ }^{14}$ but the options are expanding to include cellular phones, appliances, and a variety of web-enabled set-top options such as cable boxes, satellite decoders, and video games. Access speeds will depend on the homeowner s needs; requirements for small, infrequent data communications are lower than those for nearly continuous video clips. Also, some assurances of security and privacy are important. This multi-dimensional problem applies not only to

\footnotetext{
${ }^{10}$ This paper does not address whether or not the anticipated benefits of increased in-home IT and connectivity will outweigh the potential disadvantages (e.g., reduced social interaction and increased vulnerability to invasive prying). Our intent is to present expectations that promote connectivity as a critical infrastructure.

${ }^{11}$ Although Sweden is significantly smaller than the United States in population, its parliament is taking steps to make broadband access (which is considered a fundamental utility) a right for every citizen (Spiegler, 2000).

${ }^{12}$ DSL (digital subscriber line) technology brings high-bandwidth information to homes and small businesses over ordinary copper telephone lines.

${ }^{13}$ During the roundtable and in particular in response to questions about the future house, the term fourth utility was used to represent widespread, inconspicuous, and frequent Internet access in the home.

${ }^{14}$ In Japan, owning a computer is difficult because of cost and lack of physical space, but there are millions of e-mail-capable cellular phones in use. The Wireless Application Protocol (WAP), which allows mobile phone users Internet access and e-commerce transactions, is gaining momentum in Europe. Forrester Research estimates that only 12,000 mobile phones in Italy were regularly using WAP at the end of 1999 . . the market could grow swiftly because there are five mobile phone subscribers for every Internet PC user (Schoenung, 2000).
} 
the vulnerability of the technology, but also to the perceived ethical behavior of the entities providing on-line services.

Finally, another roundtable participant asked, What happens if all the networking occurred outside the home? Consider the number of pipes that already penetrate the walls of a home for electricity, telephone, cable, and satellite. Perhaps, in lieu of a coordinated effort to manage the progression of applications and services into the home, the network could be a series of tailored solutions for individual applications, services, and devices.

The multitude of strategies for achieving connectivity demonstrates a key characteristic that separates it from other utilities, i.e., there is no single or uniform manner in which to achieve connectivity. And there may never be. Technology and performance decisions are related to the needs of the individual (or household), which are inherently diverse. Competition and market demand will continually create better and new offerings. Therefore, making the connection is as much about choice as it is about technology.

Decomposing the factors that go into making that choice reveal some of the barriers of bringing IT and networking into the home. All of the barriers identified below except two were expressed during the industry-related events and the roundtable. We identified Nice to Have, Not a Necessity and Prescriptive Mandates Can t Keep Pace when we reviewed the roundtable discussions, but they also seemed appropriate for inclusion here.

Perceived Value. Widespread use of IT and in-home networks can occur if the technology is affordable, is intuitive to use, and, most important, has significant value. The challenge now is to show how home networks can take it to the next level, redefining how people live and spend their free time. ${ }^{15}$ It should come as no surprise that what is generally considered the single largest barrier to ushering IT into the home is consumer demand (or lack thereof). Builders, retailers, manufacturers, and market researchers at the EHE discussed the status and future of home automation. There was general agreement that a major hindrance in delivering technology to the market is lack of consumer understanding and miseducation. They [consumers] have no concept of what technology can do for them, one participant stated. Another commented that the industry focuses on technology that is possible rather than what people want.

An observation made both by EHE and roundtable attendees was that people want to know how the technology is relevant to them. For instance, if you ask the consumers if they want a home network, there s a resounding no, but if you ask them do they want to share Internet access, the answer is yes. They find out about broadband and like it because it is Internet without the wait, stated one participant. The concern appears to be that until the choice becomes a simple application-driven proposition, free of the semantic problems created by industry jargon, the public at large will find it difficult to determine what they want based on technology.

Nice to Have, Not a Necessity. The Internet is most likely the mainstay of connectivity and will be the delivery mechanism for many things, but it is not ubiquitous in homes, it is not in the background, and it is not seamlessly delivered like running water. When a home is bought and sold, it is not necessary to decide to install the water heater and the pipes that carry cold water, hot water, and waste water. In contrast, connectivity is largely a personal preference or add-on that must be consciously sought out, planned for, installed, and maintained. Individuals decide how much connectivity (bandwidth) they want and where they want it, based on their personal needs and the options of services offered. These choices are most likely made with little guarantee that the resultant infrastructure is sufficiently flexible to gracefully evolve with technology and applications over time. Builders faced with a similar uncertainty sometimes wire homes without a strong reason or clear benefit, simply because they feel it is a good idea.

No Clear Installation Methodology. Builders face daunting challenges when they install or enable technology. They often do not know what to use or where to install it, so they bundle several types of wires, such as cable, fiber, and Category $5,{ }^{16}$ and string them around a house. This is similar to the HAA s Wiring America s Homes educational campaign, which recommends a structured approach consisting of Category 5 twisted pair and RG-6 coaxial cable. ${ }^{17}$ Even though the cost to install Category 5 wire is comparable to that of cable TV, most residential

\footnotetext{
${ }^{15}$ Craig Mundie, Microsoft (see Holmes, 2000).

${ }^{16}$ Category 5 is a further extension of the EIA/TIA-568A cabling system and supports data rates up to 100 megabits per second (Mbps).

Category 3 can support data rates up to 1 Mbps. However, achieving these upper limits is dependent upon the structure of the wiring system.

${ }^{17}$ See Home Automation Association (n.d.).
} 
builders do not install it, for a variety of reasons. ${ }^{18}$ EHE attendees stated that consumers don $t$ ask for it, and adding this feature to the product doesn $t$ sell well when trying to keep the costs down. At the roundtable it was suggested that builders reluctance to install things that they are unsure of is related to their desire to avoid callbacks. Another roundtable participant noted, Liability concerns for new technology can be a significant disincentive. An alternative to installing the wiring is to install conduits and pull the wire at a later date, but it appears that builders may not choose this either, for reasons similar to those stated above. One potential solution that overcomes some of these challenges is the use of structural insulated panels (SIP). The conduit can be built into the SIP during manufacturing, thereby reducing the skill and effort required on-site.

Prescriptive Mandates Can t Keep Pace. Standards that define the components of an in-house network may make it easier to decide what to use, but they may also inhibit taking advantage of new opportunities as they occur. This is particularly true in the fast-paced world of IT. For example, due to its improved performance over that of its predecessor (Category 3), Category 5 is becoming the preferred approach. Yet in December 1999, the FCC adopted Category 3 as the standard for copper inside wiring. ${ }^{19}$ That requirement took effect in mid-2000. Mandated standards can help in deciding what to install and in ensuring interoperability, but they often lag technology. Thus, technology is often already obsolete when it is adopted.

Limited Skilled-Labor Pool. In-home networking is giving rise to a need for a new breed of skilled labor, the home systems integrator. Responsible for installation and integration of wiring schemes, control units, and sensors, these digital plumbers are becoming increasingly critical, as well as hard to find. Several labor pools, including electricians, telephone repairmen, and cable/security-system installers, are likely candidates to move into this niche market. ${ }^{20}$ Builders want a single point of contact to handle the various trades/areas associated with technology integration, which requires integrators to be knowledgeable about multiple disciplines. On the other hand, installers/integrators want simpler and more interoperable technology. An EHE participant commented, I don $t$ want to staff an engineering department just to integrate the equipment. The demand for system integrators is very high, but there aren $\mathrm{t}$ enough knowledgeable and accredited installers to get the job done, ${ }^{21}$ according to some members of the roundtable. Many of the digital plumbers in attendance at EHE also expressed concerns that the problem is exacerbated by the lack of a well-developed set of installation, diagnostics, and repair tools.

Cracking the Retrofit Market. Broad diffusion of IT and in-home networks will not occur unless the existing residences are also connected. It is uncertain whether the structured wiring and conduit approaches previously described will yield a positive cost/benefit ratio for most homes. Therefore, alternative options will be critical for existing residences, which far exceed the number of new or to-be-built homes. Two key approaches for reaching this market, frequently referred to as no new wires, are (1) the use of the existing wiring infrastructure and (2) skipping the wires altogether and going wireless.

Telephone, cable, and powerlines make up the existing wiring infrastructure. Internet, cable, and telephone companies are actively pursuing customers with offers of increased bandwidth and bundled services. However, looming nearby is another player, the local electric utility company, which may be in the best position to reach all residences. With nearly total coverage of homes, distributed delivery reaching all points within the home, and bandwidth up to $1 \mathrm{Mbps}$, digital powerlines ${ }^{22}$ may be the technology that truly provides access to all. However, despite recent product announcements and powerline trials, it does not appear that this technology is commercially available yet. ${ }^{23}$

On the surface, it would appear that wireless technology avoids many problems such as complex wiring schemes and the need for highly skilled labor to perform installation and integration. But upon closer inspection, it becomes

\footnotetext{
${ }^{18}$ Conversely, the commercial customer will most likely have specific requirements for networking in accordance with his or her business needs. Recognizing that the majority of the costs associated with wiring are labor costs, not the costs of cable, commercial builders are preparing walls for future requirements by pulling extra wire at the beginning of construction. (See Lawton, 1998.)

${ }^{19}$ See Federal Communications Commission, 2000.

${ }^{20}$ SecurityLink (part of Ameritech) is countering the shortage by capitalizing a ready labor market, namely security-system installers, as their trained installation work force. This is their business strategy to reach the "last 100 feet.

${ }^{21}$ This shortage is also impacting the ability to provide service to customers in "urban centers with high-speed infrastructure," according to Fritz McCormick, a Yankee Group analyst. (See Lake, 2000).

${ }^{22}$ This term refers to the technology that enables high-speed Internet access through standard electrical lines via a local electricity substation.

${ }^{23}$ ITRAN Communications, Ltd., recently announced a powerline modem chip that can reach broadband speeds (see Business Wire, 2000). Recently granted a patent for technology that reportedly "solves the problems of line noise, electrical load imbalances and transformer interference," Media Fusion is seeking licensing opportunities with energy providers, communication companies, and/or other companies (see www.mediafusioncorp.net/northamerica/main/).
} 
evident that wireless has its own challenges. Architectural and standards issues need to be addressed: What are the assurances for interoperability and avoiding interference? Will the current technology become obsolete and have to be replaced within the next few years? How will the system be managed for large and rapidly growing numbers of cellular devices? Who is responsible for product liability? What are the community/environmental concerns about repeaters or cellular sites to support regional communications?

Finally, a significant barrier associated with wireless may be consumer perception. Some people think it is too expensive and will always be too expensive. Until recently, wireless was very expensive, but due to increased bandwidth demand for both voice and data, a convergence of the technologies to support these services, and more competition among providers, costs have fallen and throughput has increased. Others question the safety of wireless communications. Recent events such as local communities protesting against cellular sites located near schools, warnings that children should not use cellular phones, and public announcements to keep the phone antennae away from your head exacerbate the safety/health perception issue.

Service Provider Confusion. While individuals and builders are struggling with the last 100 feet, carriers providing distribution (such as cable, DSL, and satellite) are fighting over the last mile. The good news is the last mile is deregulated, so there is choice. The bad news is the last mile is deregulated, so it s uncertain who will run it. And then there is a hybrid approach, primarily targeted to new developments, where the last mile is under the control of the builder, but some see this as less choice, since the homes are prelocked into a provider.

Wireless, shared wire, or dedicated wires, there seems to be general agreement that service providers who bundle the broadband, install the network, and provide content are sorely needed. This solution is appealing to builders because it would provide a rationale and method for establishing connectivity in homes. A participant at the AHAM conference noted, This network needs a common base because no one [manufacturer] owns the house. Poignantly, another person added, There s no shortage of technologies . . . just a shortage of agreement. This is precisely what builders want to avoid. Figuring out how to construct homes (or retrofit existing residences) to support IT/networking for a variety of applications is challenging, and current construction practices often do not facilitate finding solutions. EHE attendees made it very clear that builders want to know how to build for IT without having to become experts on the products of every vendor vying for dominance in the home. The service provider could fill this gap.

A service provider may also appeal to consumers, because it could help overcome the challenge of navigating the maze of connectivity options. The infrastructure is not the end game. It alone has no value to the homeowner, but it is a stepping stone to realizing greater benefits. People also want assurances that the technology is reliable and robust. ${ }^{24}$ The notion of increased in-home IT that is capable of enhanced monitoring, control, and communication, may be unnerving to many people, particularly if their primary exposure to technology is a computer that often hangs up or frequent false alarms from a security system. Service providers could give consumers reassurance that someone is responsible and that there is someone to call when the system doesn $t$ work or when it breaks. One roundtable participant noted that this will become particularly important as the infrastructure evolves into the background and the invisibility of the network makes problems difficult to diagnose.

\section{Bringing IT Home}

Whatever the home of the future is able to do, and whatever the network architecture is, achieving an increasingly connected society may require a partnership of industry and government. Competitive market forces and new technologies create increased options for obtaining network access from home, but it is uncertain whether the infrastructure and connectivity problem will be resolved for all residence types. It may be that such an objective can be achieved only by definitive goals set forth in policy (as was the case with rural electrification in the last century).

\section{Where Are We Now?}

This raises several questions: What percentage of homes have adequate infrastructures for this cyber environment? Is that percentage increasing and, if so, how fast is it increasing? What areas within the home are failing to keep

\footnotetext{
${ }^{24}$ Obviously, other issues related to security and privacy are of concern, but these are often closely related to the application or service. Health or financial information flowing through a network is likely to cause more concern than dissemination of video entertainment. Those areas are not discussed here, as they are treated in detail in the relevant domain literature. (See Neu, Anderson, and Bikson, 1999; National Academies News, 2000).
} 
pace? The answers to these questions may be difficult to ascertain. It is necessary to understand not only how a home is enabled for access, but also how a home facilitates networking internally.

Having a telephone line and a computer does not necessarily imply access. Table 1 shows the percentage of U.S. households that have a telephone, the percentage that have a computer, and the percentage that use the Internet. It is difficult to draw a relation among these three because Internet access is growing very rapidly, as are the options and reasons for attaining access. For example, in Sending Your Government a Message (Neu, Anderson, and Bikson, 1999), the authors address the use of e-mail for on-line transactions between government and citizens. Increasingly, these transactions will be enabled not only via computers, but also via mobile phones, appliances, set-top boxes, and public kiosks. Furthermore, the options for establishing connectivity have expanded beyond the telephone-line dialup, which many industry analysts still believe will be the dominant means of access in the near future. Access is also achieved via DSL, cable modem, and satellite TV, but these alternatives are used by only a small fraction of online consumers. ${ }^{25}$ Noticeably missing in many industry projections are technologies such as digital powerlines, which, if successful, could be a significant contender for these services.

\begin{tabular}{|c|c|c|c|}
\hline & Telephone & Computer & Internet Use \\
\hline 1994 & 93.8 & 24.1 & - \\
\hline 1997 & 93.8 & 36.6 & 18.6 \\
\hline 1998 & 94.1 & 42.1 & 26.2 \\
\hline
\end{tabular}

Table 1: Percentage of U.S. Households with Telephone, Computer, and Internet Use: 1994, 1997, 1998

Source: NTIA

Given the variety of options for in-home networking suggested in Section 2, it may be very difficult to determine how prepared homes are to support networking internally. The exception, of course, is digital powerline technology, which, if feasible, has nearly total reach and coverage within U.S. homes. However, any measure of preparedness would have to consider a range of capabilities, not simply whether the home is networked or not. Figure 1 represents a rather high level of networking within the home; it is unlikely that every home will need to meet this standard to reap the expected benefits of in-home IT and connectivity.

Even without answers to these questions, actions taken to increase in-home IT and connectivity probably should be tailored to fit specific problems. The EHE participants talked about the customer gap between the rich and famous, the do-it-yourselfers, and the average person, recognizing that the approach taken may need to differ across the distinct markets. Another characterization of technology adopters that aligns with the groupings suggested by EHE participants is innovators, early adopters, early majority, late majority, and laggards. ${ }^{26}$ It may be reasonable to expect households to differ with respect to the ease with which they take advantage of in-home IT and networking. If the government is to participate in accelerating the use of in-home IT for all citizens, then categorizing the population via such groupings is useful to the extent that it demonstrates the potential need to develop different policies and incentives for different elements of the population.

Is there a role for government in shepherding technology into America s homes? Economists generally acknowledge that some investments of crucial benefit to society as a whole will not be made by business because no single company, or even industry, will reap the benefits (Madrick, 2000). Efficient government, reduced national healthcare costs, increased energy efficiency, and improved $\mathrm{K}-12$ education may typify the societal benefits possible with increased use of IT at home. But these are difficult to quantify and even more difficult to link directly to investments. Connecting the population at large for such societal objectives may not prove very attractive to businesses where the return on investment is limited. Assuming that some housing segments will be left behind and that their integration into a connected society is necessary for the public good, the responsibility for accelerating the deployment of IT and in-home networks may rest solely with the government.

\footnotetext{
${ }^{25}$ According to Telecommunications Report International (Lake, 2000).

${ }^{26}$ These categories address the challenges of diffusing technology (see Center for Interactive Learning Technology, n.d.).
} 


\section{Potential Government Roles}

Technology for the first time holds the potential of revolutionary new solutions to real problems: from traffic and crime to health and education. Moreover, there is a huge constructive role for government policy in promoting these changes (Saylor, 2000). The question is, What are the most appropriate ways for government to push technology into the marketplace, while possibly also creating a demand pull? The roles are certainly linked to the objective, so the precise strategies used for health care, public safety, education, public transportation, and energy/environmental efficiency, particularly for low-income citizens and the elderly, will differ. Regardless of the domain, a general rule of thumb is that the government should set goals and encourage action but not dictate implementation. An industry participant at the roundtable suggested, The government should be a help, not a barrier.

The following list of constructive government roles was developed primarily from comments made during the roundtable. This government-sponsored session was held for the explicit purpose of hearing the thoughts of the assembled group of experts on what government should or should not do to promote in-home IT. Subsequent to the roundtable, the ideas were grouped into related categories and, where appropriate, expanded with definitions or references to other sources for clarification or support. No further analysis of these recommendations was performed, and the ordering of the list below is not meant to suggest any relative importance among the ideas.

1. Support standard-setting activities to foster integration and interoperation of IT in the home that will

a. Encourage the development and use of open standards for wireless technologies applicable to home networking. Standards provide the necessary guidance and foundation upon which technology can evolve while remaining compatible and interoperable. For example, standards that govern $\mathrm{HTML}^{27}$ and e-mail make it possible for different Internet applications to provide the same services. When standards are kept open and adhered to, they can enable greater participation and innovation across the industry and may provide some assurance to the user that the next new release will not spell disaster.

b. Develop minimum performance standards for IT in housing. Prescriptive standards will repeatedly be outstripped by the fast pace of technology. Specifications that characterize the type and level of performance required will help builders, retrofitters, and consumers make informed decisions about what sorts of technology to adopt in the home.

2. Sponsor R\&D to address the limitations or safety concerns of promising technologies for the home IT infrastructure.

a. The demands of society often present an opportunity to adapt technology to better meet current needs. Digital powerlines may provide such an opportunity, as they could provide an equitable and rather complete approach to the intra- and inter-home networking challenge. However, applied research is needed in powerline network access and usage to resolve issues (such as noise) that are preventing widespread deployment. Bringing this technology to the market would bring equity first and higher-quality access later, as competitive forces take effect.

b. The usability and intuitiveness of technology impact the perceived value of in-home IT. For example, the amount of information in Figure 1 and the manner in which it is disseminated may be overwhelming. There is a need for more research to obtain people s views rather than forcing them to adopt particular technology. ${ }^{28}$ This sentiment was echoed by an EHE participant who stated that intuitive technology disappears into the architecture; it s used by many but noticed by few. Collaborative efforts with industry may facilitate and keep focus on improving the usability and intuitiveness of in-home IT.

c. Research is needed on the health and safety impacts of increased use of and exposure to wireless technology within the home. Several recent announcements of industry studies are a step in the right direction, but the government must be the people s referee, as the public cannot afford to rely solely on those industries that have a vested interest in the technologies. The public will not soon forget lessons

\footnotetext{
${ }^{27}$ HTML (hypertext mark-up language) is used to publish text and images for the Web which can be viewed using any type of computer or browser.

${ }^{28}$ MIT's School of Architecture has a project called HouseN, which looks at the way people live and solve some problems with design and others with technology. The project hopes to improve education, health, connections, and transgenerational relations within the home (see http://architecture.mit.edu/house_n/).
} 
learned vis- -vis the tobacco industry s claims regarding public health impact. Consumer perception (accurate or otherwise) can be a key determinant in the success of technologies.

3. Sponsor awareness campaigns to energize targeted groups to take action.

a. The digital plumber or home-integrator labor shortages may have a ripple effect on the quality, availability, and costs of services, potentially further delaying the diffusion of in-home IT, particularly in less-affluent or less-informed segments of the population. Over time, market forces will resolve the imbalance, but increased awareness and educational opportunities, targeted particularly to those segments of the workforce that could quickly incorporate these skills, may help ease the near-term pressures.

b. When people understand the risks and benefits of technology in meaningful terms that have relevance to their homes, they are better able to make intelligent decisions about the use of technology. Making technology familiar without requiring detailed technical understanding may foster grass-roots adoption and diffusion above and beyond the provision of safety and convenience. Public-service campaigns (possibly joint public/private efforts) could be an important vehicle for educating and increasing public awareness about the benefits, challenges, and choice of in-home IT. For example, awareness could be increased via the establishment of a technology home-performance, or e-home, rating. If realtors were educated on the meaning of such ratings and could incorporate them in listing information, they could help consumers to weigh the value of technology against other home amenities such as upgraded carpeting.

4. E-governance.

If government can offer services on-line for actions such as car registration, license renewal, and filing claims, segments of the population that previously found no value in connectivity from home may find it in their best interest to be connected. It will be imperative that the on-line experience satisfy the public s need in order for this to become the preferred way to conduct business with government. Since government services are widely applicable to the population at large, this effort could reach those who are not innovators or early adopters, people that industry may not target because they cannot be up sold via the standard business model. On-line government services could help open up opportunities for other services and applications.

5. Provide incentives.

Tax policy, matching grants, and deregulation are examples of actions that could be catalysts to harness privatesector investment and motivate grass-roots efforts to increase the use of IT in the home. ${ }^{29}$ Government could consider

a. Tax credits for builders who install appropriate technology in Federal Housing Administration (FHA) qualified homes. A minimum performance standard for public housing could be used as the benchmark, thus retaining flexibility in the selection and integration of technology.

b. Tax credits for installing home equipment that enables telecommuting. A proposal announced at the ITAC Telework America Action Summit to encourage employers to consider telecommuting would provide a $\$ 500$ tax credit for every worker who telecommutes at least 75 days per year.

c. Tax credit for Internet submission of IRS forms instead of charging a fee for this option.

d. Matching grants for programs that provide access for networking beyond the home to targeted groups, similar to service policies that provide affordable telephone access. Examples include the FCC s Lifeline Assistance and Link-Up America for low-income households, the FCC s Universal Service Fund for areas that are costly to reach, and the USDA s Rural Utilities Service (RUS) for rural communities.

e. Matching grants for programs that provide capital and services for intra-home networking to targeted groups, similar to the model of PeoplePC, a membership-based program that collectively brokers and provides services for consumers through collaboration with industry partners who deliver hardware, software, Internet access, and system support at modest prices.

\footnotetext{
${ }^{29}$ Roundtable participants suggested that these actions can create an investment environment and are preferred over direct transfers, which are very hard to make. The concern was that even when the benefits can be shown, as is the case with energy efficiency, it is still difficult to demonstrate validity.
} 


\section{Conclusions}

The technological revolution created by increased proliferation of IT is yet another rung on the ladder of events promising to revolutionize American lifestyles. Previous advances in railroad, telephony, and television that brought about significant change also faced similar issues of equity, availability, and responsibility. It would be wise to take heed of the lessons learned from these technologies during their evolution. This paper has described some of the benefits of and barriers to moving IT into the home and ways in which government could facilitate this transition. Progressively more convincing arguments are being made regarding the benefits of IT in the home for individuals, communities, and society. Potential benefits include applications to make everyday life easier and safer, as well as opportunities for equitable access to educational and health resources. The benefits may also include ways in which the government can provide services to the citizens with greater efficacy and strategies to help reduce resource consumption.

The barriers to moving IT into the home are an intertwined set of political, socioeconomic, and technical challenges. Many of the barriers presented here can be summed up as a valuation problem, from the perspective of the consumer, the builder, and the service provider. People are more likely to adopt IT in the home if there is a significant reason to do so, and builders are probably willing to incorporate these technologies if there is a demand for them. The experience of using these technologies must meet the expectations and needs of the users. Technology is diffused not by the allure of devices or the network, but the expected benefits that result from it.

A portfolio of efforts across government levels and partnered with industry may be an effective means to address this complex problem. A broadly accepted position from the roundtable was that the government should pursue strategies that are technology-neutral, ${ }^{30}$ seeking to increase the delivery of on-line applications and services, while broadening the availability of access to all. In areas where there is a clear return on investment for industry, the government should stay out of the way. In areas less appealing to market forces, the government can help create incentives or partnerships that foster innovation and investment. Therefore, the appropriate role for government may be that of a motivator to encourage the use of IT in the home. Increased applications and services that provide a rationale for IT can create a grass-roots desire for it (demand pull). Incentives that prompt others to take action can unleash industry or organizational investments to disperse technology (demand push).

Section 4 listed five broad categories of government actions that could help remove some of the barriers. Three of the specific recommendations are repeated here because they suggest opportunities that may enable connectivity among nearly all citizens, activities to engage the participation of diverse stakeholders, and strategies to harness scarce resources:

- Sponsor studies to investigate and resolve technical and implementation challenges associated with the use of digital powerlines. Electric powerlines reach nearly all of the population, and they already exist in a distributed fashion in and around the home. This technology could make access an equitable and feasible commodity for all.

- Support consortia activities and partnerships to promote open industry standards for wireless technology in the home. The evolution of technology is inevitable, but changes that are made without regard for those who have already invested in technology or that have the objective of limiting participation/competition can stifle creativity and innovation and can negatively impact consumer valuations.

- Provide incentives to stimulate investment or innovation in activities that will enhance the rationale for and/or facilitate access to additional in-home IT and networking.

The events, resources, and roundtable discussions summarized here demonstrate that there are useful and practical actions that government can take to address a variety of issues related to the functionality and technological needs of the future home. One of the most critical roles that government can play is that of facilitator, bringing together the public and private sectors for consideration and practical resolution of these issues.

\footnotetext{
${ }^{30}$ Some of the roundtable participants observed that where market or research forces have not yet determined the best or right solution among competitive technologies, the government should not infer or suggest by its actions or policy the preference for any particular technology over another. This was considered especially important in issues such as wire versus wireless or fiber versus wire, and in areas where the right choice is highly situation-dependent.
} 


\section{References}

American Telemedicine Association, Telemedicine: A Brief Overview - Developed for the CongressionalTelehealth Briefing, June 23, 1999 (www.atmeda.org).

Baugh, S., and M. Matyjas, Digital PowerLine Providing Access to the Internet Through Electric Power Lines, Carnegie-Mellon University (www.andrew.cmu.edu/user/wsb/telecom/finalreport.html\#IO).

Business Wire, Itran Introduces the Itm1 - High Speed, Robust and Low Cost Power Line Chip Solution, Tel Aviv, Israel, February 16, 2000.

Center for Interactive Learning Technology, National Library of Medicine, National Institutes of Health, Technology Adoption and Diffusion (http://tlc.nlm.nih.gov/resources/publications/sourcebook/adoptiondiffusion.html).

Federal Communications Commission, Petition for Modification of RM-5643 Section 68.213 of the Commission s Rules filed by the Electronic Industries Association, January 10, 2000 (www.fcc.gov/Bureaus/Common_Carrier/Orders/2000/fcc99405.txt).

Federal Communications Commission, Common Carrier Action, News Release, January 10, 2000 (www.fcc.gov/Bureaus/Common_Carrier/News_Releases/2000/nrcc0001.txt).

Holmes, S., Home of the Future Is Being Fought Over Today, Los Angeles Times, January 10, 2000.

Home Automation Association, Get Connected for Living (www.connectedhome.org).

IDG News Service/London Bureau, Wireless Net 99: Race for Bandwidth Begins, June 3, 1999 (http://software.idg.net/crd_symons_75592.html).

Lake, D., Bandwidth Bandwagon, The Standard, May 15, 2000 (www.thestandard.com/research/metrics/display/0,2799,15018,00.html).

Lawton, S., It s the Next Generation of Copper, Wiring, February 2, 1998 (www.wcmh.com/98/98feb/802a054a.html).

Madrick, J., Government s Role in the New Economy Is Not a Cheap or Easy One, The New York Times, May 11, 2000.

National Academies News, Significant Technological Barriers Remain for Providing Health Care on the Internet, February 23, 2000 (http://www4.nationalacademies.org/news.nsf/).

National Telecommunications and Information Administration (NTIA), Falling Through the Net: Defining the Digital Divide, February 23, 2000 (www.ntia.doc.gov/ntiahome/fttn99/contents.html).

Neu, C. R., R. H. Anderson, and T. K. Bikson, Sending Your Government a Message: E-mail Communication Between Citizens and Government, Santa Monica, CA: RAND MR-1095-MF, 1999.

Saylor, M., The Missing Issue, The Washington Post, March 14, 2000.

Schoenung, M., Italy Dialed in to Wireless Net, Wired News, May 8, 2000 (www.wired.com/news/technology/0,1282,36048,00.html).

Spiegler, M., Life, Liberty and Broadband, The Standard, May 15, 2000 (www.thestandard.com/article/display/0,1151,15008,00.html).

Symonds, M., After e-Commerce, Get Ready for e-Government, The Economist, June 24, 2000 (www.economist.com/editorial/freeforall/20000624/index_survey.html).

Telecoms \& Broadcast, Power Line Communications World Congress, May 20, 1999 (www.iir-conference.com/powerline2.html). 


\section{Appendix A: Roundtable Participants}

Colton R. Alton

eCollege.com

Ray Appel

Oakwood Homes

Doug Arent

Lucent Technologies

Leon Baumgarten

NextBus Information Systems, Inc.

Mark Bernstein

RAND

Tora Bikson

RAND

Peg Brown

The Dutko Group, Inc.

Ray Downs

Office of Science and Technology Policy

White House

Stephanie Harmon

Fannie Mae Colorado Partnership Office

Scott Hassell

RAND

James E. Hodges

International Conference of Building Officials
Rosalind Lewis

RAND

Jimm Meloy

Worldwide Learning \& Training

Autodesk, Inc.

David Nash

Intel Corporation

Robert Neches

University of Southern California

Information Sciences Institute

Allan Schurr

Silicon Energy

Stephen Selkowitz

Lawrence Berkeley National Laboratory

Jay Stark

Lee Homes

David Wang

Lucent Technologies 


\section{Appendix B: Workshop Series Sponsors}

\section{PATH (www.pathnet.org)}

The Partnership for Advancing Technology in Housing (PATH) is a voluntary public/private-sector initiative that seeks to accelerate the creation and widespread use of advanced technologies to radically improve the quality, durability, environmental performance, energy efficiency, and affordability of our nation s housing. PATH was created following a three-year, government and industry process to establish National Construction Goals for the residential construction industry. The organization s program goals build on the consensus set of goals that were established through the National Construction Goals process and are documented in Building Better Homes at Lower Costs: The Industry Implementation Plan for the Residential National Construction Goals.

PATH links key agencies in the federal government with leaders from the home-building, product-manufacturing, insurance, financial, and regulatory communities in a unique partnership focused on technological innovation in the American housing industry. During the next decade, the partnership aims to develop approaches, innovative housing components, designs, and production methods that will reduce by 50 percent the time needed to move quality technologies to market. These technologies will make it possible to produce increasingly affordable and attractive housing.

\section{NAHB Research Center (www.nahbrc.org)}

The NAHB Research Center was founded in 1964 as a separately incorporated, wholly owned, not-for-profit subsidiary of the National Association of Home Builders (NAHB). NAHB has 200,000 members, including more than 50,000 members who build more than 80 percent of all U.S. homes.

The Research Center keeps U.S. home builders in tune with new technology and changing needs. Through its programs, including testing and certification of building products, the Research Center helps American homes maintain premier status in a global industry. The Research Center, located near Washington, D.C., has a professional staff of 80 persons, including scientists, engineers, economists, architects, planners, and professionals in related disciplines. Testing and certification programs are carried out in a highly advanced, fully equipped laboratory.

\section{White House Office of Science \& Technology Policy (http://www.whitehouse.gov/WH/EOP/OSTP/html/OSTP Home.html)}

The federal government plays a critical investment role in maintaining American leadership in science and technology. In 1976, the Office of Science \& Technology Policy (OSTP) was created to provide the President with timely policy advice and to coordinate the nation s science and technology investment. OSTP has assumed a prominent role in advancing the Clinton Administration s agenda in fundamental science, education, and scientific literacy, investment in applied research, and international cooperation. 